\title{
NEWS: the 2018 Metabolomics publication awards
}

\section{Royston Goodacre ${ }^{1}$}

๑) Springer Science+Business Media, LLC, part of Springer Nature 2018

Every journal publishes papers and reviews that they are very proud of, and Metabolomics is no different. In order to recognize the excellent research published in this journal the following prizes will be awarded to the most downloaded original articles and reviews published in the previous year:

- Best Paper Award-for the Original Article with the highest total number of downloads during the previous year. The first author of the winning paper receives a complementary ebook from Springer (value $200 €$ ), a front cover image in the Metabolomics journal, and the paper will be made freely available for 30 days.

- The runner-up paper will also be made freely available for 30 days.

- Best Review Award-for the Review Article with the highest total number of downloads during the previous year. The first author of the winning paper receives complementary e-books from Springer (value $200 €$ ), a front cover image in the Metabolomics journal, and the paper will be made freely available for 30 days.

- The runner-up review will also be made freely available for 30 days.

In order for a paper to be eligible for these awards it must be either a primary research paper (which may include best practice or standards articles, as well as letters and short communications) or a review article (which includes white papers) that was published in its final form in 2017. All awards will be based on popularity via downloads.

Congratulations to the following 2018 winners!!!

Royston Goodacre

roy.goodacre@manchester.ac.uk

1 School of Chemistry, University of Manchester, Manchester, UK

\section{Best paper award}

- Winner-Zhang, Q., Ford, L.A., Evans, A.M. \& Toal, D.R. (2017) Structure elucidation of metabolite x 17299 by interpretation of mass spectrometric data. Metabolomics 13: 92. https://doi.org/10.1007/S11306-017-1231$\mathrm{X}$

- Runner up-Weber, R.J.M., Lawson, T.N., Salek, R.M., Ebbels, T.M.D., Glen, R.C., Goodacre, R., Griffin, J.L., Haug, K., Koulman, A., Moreno, P., Ralser, M., Steinbeck, C., Dunn, W.B. \& Viant, M.R. (2017) Computational tools and workflows in metabolomics: An international survey highlights the opportunity for harmonisation through Galaxy. Metabolomics 13: 12. https ://doi.org/10.1007/S11306-016-1147-X

\section{Best review award}

- Winner-Spicer, R., Salek, R.M., Moreno, P., Cañueto, D. \& Steinbeck, C. (2017) Navigating freely-available software tools for metabolomics analysis. Metabolomics 13: 106. https://doi.org/10.1007/S11306-017-1242-7.

- Runner up-Torell, F., Bennett, K., Rännar, S., Lundstedt-Enkel, K., Lundstedt, T. \& Trygg, J. (2017) The effects of thawing on the plasma metabolome: Evaluating differences between thawed plasma and multi-organ samples. Metabolomics 13: 66. https://doi.org/10.1007/ S11306-017-1196-9 